\title{
Immunosuppressive properties of follicular fluid from preovulatory horse follicles
}

\author{
E. D. Watson and H. G. Zanecosky \\ Section of Reproductive Studies, University of Pennsylvania School of Veterinary Medicine, \\ New Bolton Center, Kennett Square, PA 19348, USA
}

\begin{abstract}
Summary. Fluid was aspirated from the preovulatory follicles of mares before and 12 , 24 and $36 \mathrm{~h}$ after intravenous administration of hCG. Follicular fluid significantly $(P<0.001)$ reduced lymphocyte blastogenesis in vitro and, at a dilution of 1:100, fluid collected at $36 \mathrm{~h}$ after administration of hCG was significantly more suppressive $(P<0.01)$ than fluid collected before $36 \mathrm{~h}$. Suppression of blastogenesis was reduced by extracting the follicular fluid with ether or by charcoal treatment $(P<0.01)$ or by heating at $56^{\circ} \mathrm{C}$ for $30 \mathrm{~min}(P<0.05)$. Preincubation of lymphocytes with 2 of 5 follicular fluid samples expressed subsequent blastogenesis. Follicular fluid inhibited blastogenesis of T-cell growth factor (TCGF)-dependent Con A lymphoblasts $(P<0.05)$ and the degree of inhibition was related to time of addition of the TCGF and time of collection of the follicular fluid. These results indicate that preovulatory follicular fluid in the mare is increasingly suppressive to lymphocytes as time of ovulation approaches and that this immunosuppression is associated with an alteration of the response to lymphokine stimulation.
\end{abstract}

Keywords: mare; immunosuppression; follicular fluid

\section{Introduction}

Both the oocyte and fertilized ovum are potentially antigenic to the maternal immune system and may be susceptible to the mare's immune defence mechanisms. As the process of ovulation is believed to be an inflammatory response (Espey, 1980), it is important that the inflammatory reaction be curbed before it proceeds to an immune response. In several species, including the horse, antibodies to the zona pellucida have been detected and can prevent spermatozoa from attaching and penetrating ova (Ownby \& Shivers, 1972; Glass \& Hanson, 1974; Trounson et al., 1980; Shivers \& Liu, 1982). It has also been shown that antibodies directed against the zona pellucida can inhibit shedding of the zona by the embryo (Dudkiewicz et al., 1975).

The preovulatory follicle in the mare ovulates when it reaches a mean diameter of $45 \mathrm{~mm}$ (Pierson \& Ginther, 1985). At ovulation, the infundibulum surrounds the ovary to facilitate passage of the oocyte to the ampulla. This means that, in addition to the oocyte, approximately $45 \mathrm{ml}$ follicular fluid theoretically will pass into the oviduct. It seems possible, therefore, that substances are normally present in follicular fluid which protect the oocyte and developing embryo by suppressing the maternal immune system. Ultrasonographic results suggest that much of the evacuated fluid does not collect in the ipsilateral oviduct (Townson \& Ginther, 1989), but the oviduct in ovulating mares was not positively identified. Follicular fluid from women (Fahmi et al., 1985) and cattle (Castilla et al., 1988) suppresses mitogen-induced lymphocyte blastogenesis in vitro and in women this mechanism appears to operate via induction of suppressor cell activity (Castilla $e t a l$, 1988). Suppressor/cytotoxic lymphocytes (T8) have also been detected in follicular fluid from women (Hill et al., 1987). 
The present study investigated the effect on mitogen-induced lymphocyte blastogenesis of plasma or of follicular fluid collected from preovulatory follicles of mares at different intervals after administration of hCG. T-cell growth factors (TCGF), which are mainly interleukin-2 (IL-2) (Oldham \& Williams, 1984), are produced by activated T lymphocytes to induce clonal proliferation of T cells. By adding a source of TCGF to activated lymphocytes, it was possible to test whether follicular fluid interfered with TCGF-induced blastogenesis.

\section{Materials and Methods}

Animals and experimental design. Normally cycling, light breed horse mares aged between 3 and 16 years were used. Oestrus was detected by use of a teaser stallion. From the first day of oestrus, each mare's ovaries were examined by ultrasonography. On the day that the preovulatory follicle reached $35 \mathrm{~mm}, 2500 \mathrm{i}$.u. hCG (Butler Co., Columbus, OH, USA) were administered intravenously. Follicular fluid was aspirated either before administration of hCG or 12, 24 or $36 \mathrm{~h}$ later. Follicular fluid from 4 mares was aspirated at each time interval: 1 of the mares at $12 \mathrm{~h}, 1$ at $36 \mathrm{~h}$ and 2 at $24 \mathrm{~h}$ had two preovulatory follicles of equivalent size. In these mares, fluid was aspirated from both follicles. At the time of aspiration, blood was collected from the jugular vein into a heparinized evacuated tube. Plasma was stored at $-20^{\circ} \mathrm{C}$.

Aspiration of follicular fluid. Follicular fluid was aspirated using a technique described previously in which, after appropriate sedation and analgesia of the mare, the ovary was held by a hand inserted into the abdomen via an incision in the cranial vagina and the fluid aspirated via a needle inserted through the flank (Hinrichs \& Kenney, 1987). After collection, the follicular fluid was stored on ice until centrifuged at $2000 \mathrm{~g}$ for $10 \mathrm{~min}$ at $4^{\circ} \mathrm{C}$. The supernatant was then stored in aliquants at $-70^{\circ} \mathrm{C}$. None of the samples contained significant red blood cell contamination.

Follicular fluid treatments. Follicular fluid collected from follicles $36 \mathrm{~h}$ after administration of hCG was subjected to various treatments: (1) $25 \mathrm{mg}$ charcoal was added to $0.75 \mathrm{ml}$ follicular fluid and incubated at room temperature for $30 \mathrm{~min}$ with frequent agitation. The mixture was then centrifuged at $2000 \mathrm{~g}$ for $1 \mathrm{~h}$ at $4^{\circ} \mathrm{C}$ and the supernatant removed and added to a lymphocyte blastogenesis assay. (2) The fluid was heated at $56^{\circ} \mathrm{C}$ for $30 \mathrm{~min}$ before being included in the assay. (3) The fluid $(1 \mathrm{ml})$ was extracted twice with ethyl ether $(15 \mathrm{ml})$. The extract was resuspended in 1 ml medium and both the extract and the follicular fluid were added to a lymphocyte blastogenesis assay. Blastogenesis results were compared with wells containing medium which had been subjected to the same treatments.

Lymphocyte blastogenesis assay. Lymphocytes were isolated from blood of a healthy mare and the assay performed as previously described (Watson, 1990). Follicular fluid $(100 \mu l)$, undiluted and at dilutions of 1:20 and 1:100 or plasma collected at the time of aspiration $(100 \mu \mathrm{l} ; 1: 20)$ was added to wells containing lymphocytes $\left(1 \times 10^{5}\right)$ and concanavalin A (Con A $50 \mu \mathrm{l}, 20 \mu \mathrm{g} / \mathrm{ml}$; Sigma Chemical Co, St Louis, MO, USA). Control wells were included in which medium was substituted for follicular fluid or for Con A. After $72 \mathrm{~h}$ incubation, $0.5 \mu \mathrm{Ci}\left[{ }^{3} \mathrm{H}\right]$ thymidine (sp. act. $6.7 \mathrm{Ci} / \mathrm{mmol}$ : New England Nuclear, Boston, MA, USA) was added to each well. The wells were harvested $6 \mathrm{~h}$ later. Each follicular fluid or plasma sample was added to wells in quadruplicate.

TCGF production by mitogen-treated cells. Peripheral blood mononuclear cells were isolated as peviously described (Watson, 1990) and were cultured with $80 \mu \mathrm{g}$ Con A/ml for $2 \mathrm{~h}$ as described by Oldham \& Williams (1984). Control cultures were performed in the absence of Con A. Cells were washed twice before being incubated for an additional $24 \mathrm{~h}$. The medium was then harvested by centrifugation at $2000 \mathrm{~g}$ for $10 \mathrm{~min}$ and the supernatant stored in aliquants at $-70^{\circ} \mathrm{C}$.

TCGF assay. TCGF-dependent cells were produced as previously described (Oldham \& Williams, 1984) by culturing mononuclear cells with Con $\mathrm{A}(5 \mu \mathrm{g} / \mathrm{ml})$ for 4 days. Cells were washed twice and resuspended at $2 \times 10^{5} / \mathrm{ml}$ before being used in the assay. Serial 2 -fold dilutions of the TCGF cell supernatants $(100 \mu l)$ plus $100 \mu 1$ medium were added to triplicate cultures of cells $(50 \mu \mathrm{l})$. A l:2 dilution of the TCGF supernatant was added to wells containing cells plus follicular fluid $(100 \mu \mathrm{l})$. After a $24-\mathrm{h}$ incubation, $\left[{ }^{3} \mathrm{H}\right]$ thymidine $(1 \mu \mathrm{Ci})$ was added to each well and harvested after a further $18 \mathrm{~h}$. Control wells were included in which medium replaced the TCGF supernatant. In another assay, TCGF supernatant was added $6 \mathrm{~h}$ after the start of the assay.

Induction of suppressor cells. Mononuclear cells were preincubated for $48 \mathrm{~h}$ at $37^{\circ} \mathrm{C}$ in an humidified atmosphere of $5 \% \mathrm{CO}_{2}: 95 \%$ air with a $1: 2$ dilution of follicular fluid aspirated $36 \mathrm{~h}$ after $\mathrm{hCG}$. Controls were included in which follicular fluid was replaced by complete medium (RPMI-1640 containing 10\% fetal calf serum, $10^{-5} \mathrm{M}$-2-mercaptoethanol, $20 \mathrm{~mm}$-Hepes, $2 \mathrm{mM}$-L-glutamine, 50 units penicillin $/ \mathrm{ml}, 50 \mu \mathrm{g}$ streptomycin $/ \mathrm{ml}$ ). The cells were then washed twice and resuspended at $2 \times 10^{6} / \mathrm{ml}$. These cells $(50 \mu \mathrm{l})$ were then added to wells containing freshly prepared autologous blood mononuclear cells $\left(50 \mu 1,2 \times 10^{6} / \mathrm{ml}\right)$ and included in a lymphocyte blastogenesis assay.

Determination of cell viability. In each assay, wells were included in which $\left[{ }^{3} \mathrm{H}\right]$ thymidine was replaced by complete medium. At the end of the assay, the viability of the cells was assessed by exclusion of trypan blue dye.

Statistical analyses. Degree of suppression of $\left[{ }^{3} \mathrm{H}\right]$ thymidine incorporation was expressed as a percentage of c.p.m. in control wells. A one-way or repeated measures analysis of variance was performed to analyse effects of treatment. 
When appropriate, means were compared using the least significant difference equation. Results were considered significant when $P<0.05$.

\section{Results}

Follicular fluid undiluted and at a dilution of 1:20 significantly suppressed lymphocyte blastogenesis (Fig. 1). At a dilution of 1:100, only fluid collected $36 \mathrm{~h}$ after hCG was significantly immunosuppressive. Undiluted follicular fluid was equally suppressive at all collection times. At a 1:20 dilution, follicular fluid collected at $36 \mathrm{~h}$ was more suppressive $(P<0.05)$ than fluid collected at $12 \mathrm{~h}$ and tended $(P<0 \cdot 1)$ to be more suppressive than fluid collected at 0 and $24 \mathrm{~h}$. When diluted to 1:100, follicular fluid collected at $36 \mathrm{~h}$ was significantly $(P<0.01)$ more suppressive than fluid collected at other time intervals. Viabilities of cells suspended in undiluted follicular fluid were $76.3 \pm 5.4 \%$ in $0 \mathrm{~h}, 92 \cdot 0 \pm 3.7 \%$ in $12 \mathrm{~h}, 90 \cdot 0 \pm 1.5 \%$ in $24 \mathrm{~h}$, and $88.0 \pm 2.8 \%$ in fluid collected $36 \mathrm{~h}$ after administration of hCG. Viability in medium was $86.7 \pm 2.9 \%$. Addition of plasma to wells only slightly suppressed blastogenesis $(0.05<P<0.1)$ compared with control wells $(0 \mathrm{~h}$, $73 \cdot 1 \pm 2 \cdot 9 \% ; 12 \mathrm{~h}, 91 \cdot 7 \pm 6 \cdot 5 \% ; 24 \mathrm{~h}, 87 \cdot 1 \pm 6 \cdot 1 \% ; 36 \mathrm{~h}, 76 \cdot 4 \pm 7 \cdot 4 \%)$. Although ether extraction, charcoal stripping, and heat treatment reduced suppression of blastogenesis by follicular fluid $(21 \pm 3.9 \%, P<0.01 ; 16.1 \pm 2.3 \%, P<0.01$; and $11.9 \pm 3.3 \%, P<0.05$; respectively), the fluid still significantly suppressed blastogenesis $(P<0 \cdot 001)$. When cells were preincubated in follicular fluid for $48 \mathrm{~h}$ before assay (Table 1), 2 of the 5 follicular fluid samples collected $36 \mathrm{~h}$ after administration of hCG induced suppressor cell activity. Blastogenic response to TCGF was inhibited

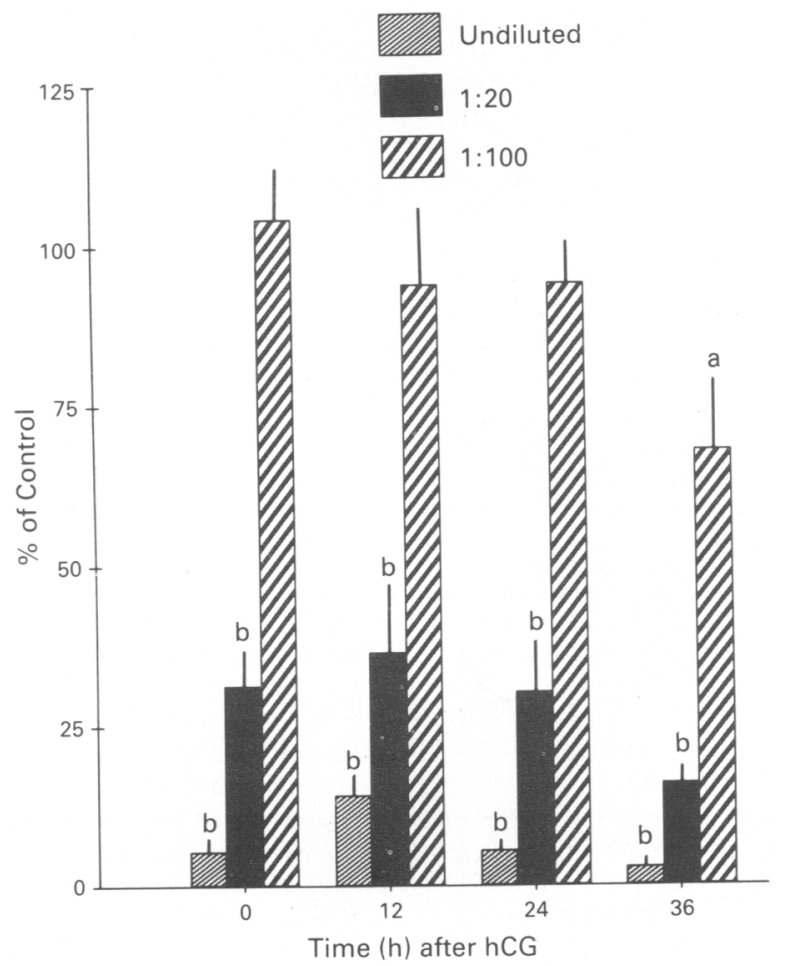

Fig. 1. Effect of follicular fluid on Con A-induced lymphocyte blastogenesis. Follicular fluid collected $0(n=4), 12(n=5), 24(n=6)$, and $36(n=5) \mathrm{h}$ after administration of hCG was added to wells undiluted and at dilutions of $1: 20$ and 1:100. Results are expressed as \% of control wells which did not contain follicular fluid. Values with superscripts are significantly different from controls. a, $P<0.01 ;$ b,$P<0.001$. 


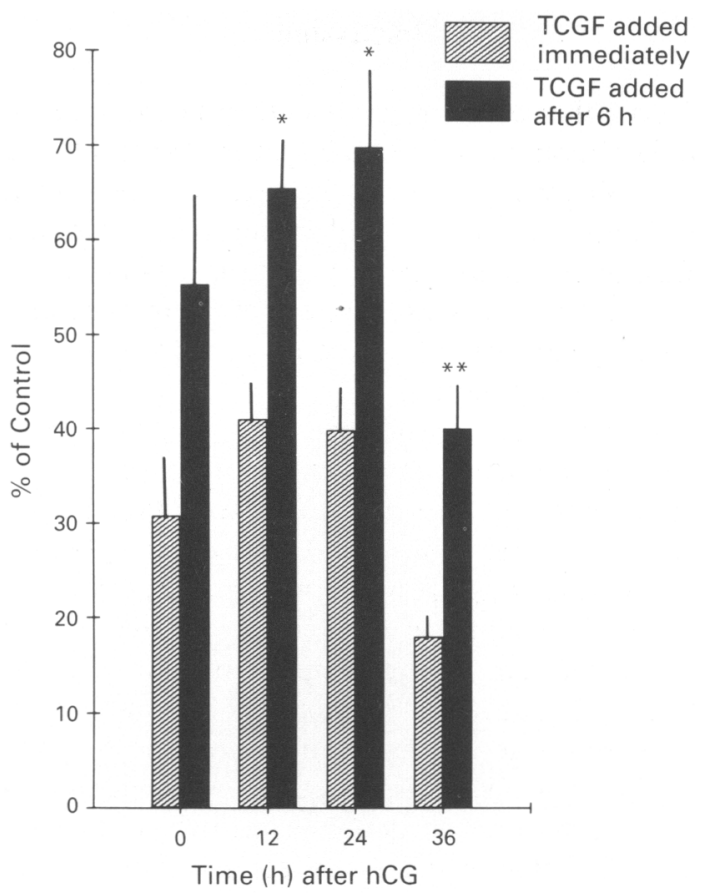

Fig. 2. Effect of follicular fluid on TCGF-induced lymphocyte blastogenesis. Follicular fluid was added to wells and supernatant containing TCGF was then added immediately or $6 \mathrm{~h}$ after the beginning of the assay. Results are expressed as \% of control wells which did not contain follicular fluid. ${ }^{*} P<0.05 ;{ }^{*} P<0.01$. Significant difference in immunosuppression between addition of TCGF at the start of the assay or $6 \mathrm{~h}$ later.

Table 1. Effect of preincubation of cells for $48 \mathrm{~h}$ with follicular fluid on subsequent blastogenesis

\begin{tabular}{lc}
\hline Preincubation medium & $\begin{array}{c}\text { Incorporation of } \\
{\left[{ }^{3} \text { H }\right] \text { thymidine (c.p.m.) }}\end{array}$ \\
\hline Follicular fluid 1 & $26227 \pm 639$ \\
Follicular fluid 2 & $27022 \pm 598$ \\
Follicular fluid 3 & $14339 \pm 1261^{\mathrm{a}}$ \\
Follicular fluid 4 & $19907 \pm 1261$ \\
Follicular fluid 5 & $18734 \pm 1322^{\mathrm{b}}$ \\
Medium & $22363 \pm 1566$ \\
\hline
\end{tabular}

Values are the mean \pm s.e.m. of 4 replicate wells.

Figures with superscripts are significantly different from control. a, $P<0.001 ;$ b, $P<0.05$.

$(P<0.001)$ after addition of follicular fluid (Fig. 2). When addition of TCGF was delayed by $6 \mathrm{~h}$, immunosuppression was reduced in wells containing follicular fluid collected at 12,24 and $36 \mathrm{~h}$ compared with wells in which TCGF was added at the start of assay. 


\section{Discussion}

This study showed that fluid collected from preovulatory horse follicles suppressed lymphocyte blastogenesis, apparently via alteration of the IL-2 system. When hCG is administered to mares which have a follicle approximately $35 \mathrm{~mm}$ in diameter in their ovaries, ovulation normally occurs within 36-48 h (Duchamp et al., 1987). The present results show that the degree of immunosuppression by follicular fluid increased as time of ovulation approached. Previous work with cattle (Fahmi et al., 1985) showed that large follicles possessed more immunosuppressive activity than did small follicles and preovulatory follicles, but there appears to be no information on fluid from maturing preovulatory follicles in any species.

Follicular fluid is formed in part by transudation from serum (Edwards, 1974; Andersen et al., 1976). Little immunosuppressive activity was present in plasma and no differences were detected between samples collected at different time intervals after administration of hCG. It therefore seems likely that, as in the cow (Fahmi et al., 1985), the lymphocyte inhibitory factors are either locally produced or selectively transported from plasma into the follicles.

Measurements of lymphocyte viability revealed similar survival rates between cells cultured in follicular fluid and in control wells containing complete medium. The immunosuppressive effect was therefore not mediated by lymphocyte cytotoxicity. Follicular fluid collected from women suppressed the proliferative response of autologous lymphocytes by inducing or enhancing suppressor cell activity (Castilla et al., 1988). Such activity was apparent in only 2 of 5 follicles when mare follicular fluid was preincubated with lymphocytes before their inclusion in a lymphocyte blastogenesis assay. Differences between individual cows in immunosuppressive factors in preovulatory follicular fluid have been reported by Fahmi et al. (1985) and these workers suggested that it was advisable to study samples from individual animals, rather than pooled samples, around the time of ovulation.

It appeared that follicular fluid interfered with TCGF induction of lymphocyte blastogenesis. When addition of TCGF was delayed by $6 \mathrm{~h}$, suppression of lymphocyte blastogenesis was significantly decreased. This suggests that follicular fluid was not merely binding TCGF directly, making them unavailable for lymphocyte stimulation, or masking IL-2 receptors. The follicular fluid could have been acting to suppress protein synthesis within the lymphocytes, reducing IL-2 receptor expression and blastogenesis. If the action of follicular fluid was to decrease TCGF production, blastogenesis should not have been suppressed in the present experiment in the presence of a source of exogenous TCGF.

As the follicle of the mare matures towards ovulation, many hormonal changes occur within the follicular fluid (E. D. Watson \& P. L. Sertich, unpublished). In particular, there are large increases in concentrations of progesterone, PGF, PGE-2 and 6-keto-PGF-1 $\alpha$ between 24 and $36 \mathrm{~h}$ after administration of the hCG. High concentrations of progesterone are known to suppress lymphocyte blastogenesis (Low \& Hansen, 1988) and PGE-2 suppresses both mitogen- and IL-2stimulated lymphocyte blastogenesis in cows, ewes (Low \& Hansen, 1988), and mares (E. D. Watson, unpublished data). The present study shows that hormones in follicular fluid may be acting to suppress lymphocyte blastogenesis, thereby reducing the immune response of the mare to antigens from the oocyte and the embryo. Treatment of follicular fluid with charcoal, heat, and ether extraction of the fluid slightly reduced its suppressive effect on lymphocyte blastogenesis. Both charcoal treatment and ether extraction would remove prostaglandins and gonadal steroids from the fluid but not proteins. It therefore appears likely that the former substances are contributing to the immunosuppression. By contrast, Fahmi et al. (1985) found that the lymphocyte inhibitory factors present in bovine follicular fluid were heat-labile which ruled out the possibility that gonadal steroids were responsible. In our study, the high degree of immunosuppression still present after treatments indicates that the main inhibitory factor(s) remains unknown but may be a protein rather than steroid. In conclusion, follicular fluid from mares possess immunosuppressive properties which may function to inhibit an oviducal immune response to the zona pellucida. 
This study was funded by the Marion Dilley and David George Jones Trust and by the Philip B. Hofmann 1966 Charitable Trust. We thank Dr Patricia L. Sertich for performing the follicular aspirations.

\section{References}

Andersen, M.M., Kroll, J., Byskov, A.G. \& Faber, M. (1976) Protein composition in the fluid of individual, bovine follicles. J. Reprod. Fert. 48, 109-118.

Castilla, J.A., Molina, R., Garcia, G., Swarez, F., LopezNevot, M.A., Vergara, F. \& Garrido, F. (1988) Induction of suppressor cell activity by human follicular fluid. Human Reprod. Suppl. 3, Abstr. 215.

Duchamp, G., Bour, B., Combarnous, Y. \& Palmer, E. (1987) Alternative solutions to hCG induction of ovulation in the mare. J. Reprod. Fert., Suppl. 35, $221-228$

Dudkiewicz, A.B., Noske, I.G. \& Shivers, C.A. (1975) Inhibition of implantation in the golden hamster by zona-precipitating antibody. Fert. Steril. 26, 686-694.

Edwards, R.G. (1974) Follicular fluid. J. Reprod. Fert. 37, 189-219.

Espey, L.L. (1980) Ovulation as an inflammatory reaction -a hypothesis. Biol. Reprod. 22, 73-106.

Fahmi, H.A., Hunter, A.G., Markham, R.J.F. \& Seguin, B.E. (1985) Immunosuppressive activity of bovine follicular fluid on bovine T lymphocytes in vitro. $J$. Dairy Sci. 68, 3312-3317.

Glass, L.E. \& Hanson, J.E. (1974) An immunologic approach to contraception: localization of antiembryo and antizona pellucida serum during mouse preimplantation development. Fert. Steril. 25, 484-493.

Hill, J.A., Bourbieri, R.L. \& Anderson, D.J. (1987) Detection of T8 (suppressor/cytotoxic) lymphocytes in human ovarian follicular fluid. Fert. Steril. 47, 114-117.

Hinrichs, K. \& Kenney, R.M. (1987) A colpotomy procedure to increase oocyte recovery rates on aspiration of equine preovulatory follicles. Theriogenology 27, Abstr. 237.

Low, B.G. \& Hansen, P.J. (1988) Actions of steroids and prostaglandins secreted by the placenta and uterus of the cow and ewe on lymphocyte proliferation. Am.J. Reprod. Immunol. Microbiol. 18, 71-75.

Oldham, G. \& Williams, L. (1984) Interleukin-2 (IL-2) production by mitogen stimulated bovine peripheral blood lymphocytes and its assay. Vet. Immunol. Immunopathol. 7, 201-212.

Ownby, C.L. \& Shivers, C.A. (1972) Antigens of the hamster ovary and effects of anti-ovary serum on eggs. Biol. Reprod. 6, 310-318.

Pierson, R.A. \& Ginther, O.J.(1985) Ultrasonicevaluation of the preovulatory follicle in the mare. Theriogenology 24, 359-368.

Shivers, C.A. \& Liu, I.K.M. (1982) Inhibition of sperm binding to porcine ova by antibodies to equine zonae pellucidae. J. Reprod. Fert., Suppl. 32, 315-318.

Townson, D.H. \& Ginther, O.J. (1989) Ultrasonic characterization of follicular evaluation during ovulation and fate of the discharged follicular fluid in mares. Anim. Reprod. Sci. 20, 131-141.

Trounson, A.O., Shivers, C.A., McMaster, R. \& Lopata, A. (1980) Inhibition of sperm binding and fertilization of human ova by antibody to porcine zona pellucida and human sera. Archs Androl. 4, 29-36.

Watson, E.D. (1990) Suppression of lymphocyte reactivity by culture supernatant from horse embryos and endometrium. Biol. Reprod., 42, 294-300.

Received 9 November 1989 